Asian J. Med. Biol. Res. 2018, 4 (1), 123-131; doi: 10.3329/ajmbr.v4i1.36830

\author{
Asian Journal of \\ Medical and Biological Research \\ ISSN 2411-4472 (Print) 2412-5571 (Online) \\ www.ebupress.com/journal/ajmbr
}

\title{
Article \\ Socio-demographic characteristics, dietary habits and physical activity influence on nutritional status of the diabetics: a cross sectional study
}

\author{
Hasan Mahfuz Reza ${ }^{1}$, Md. Rezaul Karim² and Md. Abdus Samad²* \\ ${ }^{1}$ Department of Applied Nutrition and Food Technology, Islamic University, Kushtia, Bangladesh \\ ${ }^{2}$ Department of Applied Nutrition and Food Technology, Islamic University, Kushtia, Bangladesh
}

*Corresponding author: Md. Abdus Samad, Professor, Department of Applied Nutrition and Food Technology, Islamic University, Kushtia, Bangladesh. Phone: +8801735460984; E-mail: samadanft@gmail.com

Received: 07 March 2018/Accepted: 26 March 2018/ Published: 29 March 2018

\begin{abstract}
Diabetes mellitus, a chronic, debilitating disease, is associated with a range of severe complications which include cardiovascular disease, renal disease and blindness. Demographic and epidemiological evidences suggest that the incidence of diabetes is increasing worldwide. Diabetes mellitus in people of all ages is reaching epidemic proportions in Bangladesh. The main objective of this cross sectional study was carried out to evaluate that nutritional status of the diabetic patients influence by socio-economic level, dietary habits and physical activity.A total of 282 diabetic outpatients were recruited using Simple Random Sampling technique from three referral diabetic centers namely-Kushtia Diabetic Shomity, Bheramara Diabetic Shomity and Diabetic Shomity Kumarkhali, Kushtia, Bangladesh. The nutritional status of each participant was screened. Direct method of nutritional assessment including anthropometric measurement, biochemical measurement, clinical assessment and dietary method was carried out. Socio economic data were also collected. Data were analyzed using the computer program Statistical Package for Social Sciences (SPSS) version 22.The result reveals that51.1\% $(n=144)$ of the total participants were male and $48.9 \%(n=138)$ were female. About $28.4 \%$ population studied were between 51-60 years, 94.7\% married, 44.7\% were unemployed and 50.4\% were resided in urban area. Based on Body Mass Index (BMI), mean BMI of male was $23.32 \pm 3.47$ and that of female was $25.83 \pm 4.46$, half of the respondents $(48.9 \%)$ had an acceptable nutritional status with a BMI between 18.5-24.9 (62.3\% male; $37.7 \%$ female) whilst $4.6 \%$ of the respondents were underweight with BIMs below 18.5 . The female who were observed were $22(88.0 \%)$ and the male were $3(12.0 \%)$ showing a very great prevalence of obesity (BMI more than 30.0). Study showed that $98(34.7 \%)$ respondents bear diabetes from their family and $147(52.1 \%)$ respondents have family history of hypertension The mean blood hemoglobin level was $12.49 \pm 1.47 \mathrm{~g} / \mathrm{dl}$, in which male hemoglobin level was $12.85 \pm 1.48 \mathrm{~g} / \mathrm{dl}$ and of female was $12.11 \pm 1.36 \mathrm{~g} / \mathrm{dl}$. The result shows that about $29.8 \%(n=84)$ patients had no formal education; among them more were female $65.5 \%(n=55)$. More of the patient $(50.7 \%)$ had family member of $4-6$. About $33.0 \%$ of the studied patients were low-income level (25.9\% were from upper-lower and 7.1\% were from lower socio-economic status). Among 37.6\% ( $\mathrm{n}=106)$ overweight (BMI 25.0-29.9) diabetic patients more were female 56.6\% $(\mathrm{n}=60)$ and $55.7 \%(\mathrm{n}=59)$ were unemployed. So, female sex, lower educational status, more family member, low monthly family income group and unemployment are associated with malnutrition. Unemployed housewives represented to have both extremes of nutritional status- under nutrition and over nutrition. In the study, most of the patient $126(44.7 \%)$ were unemployed, among them almost all the patient 124 (98.4\%) were female. Diabetic care seeking by rural people and female appeared encouraging emphasizing the need of decentralization of diabetic care center to periphery.
\end{abstract}

Keywords: diabetes; malnutrition; body mass index; hemoglobin; medical nutrition therapy 


\section{Introduction}

Diabetes is a chronic condition characterized by hyperglycemia. It is caused by deficient insulin production, resistance to insulin action or a combination of both (Alberti and Zimmet, 1998). It is accompanied in many cases by secondary alteration of fat and protein metabolism resulting in an array of physical disorder. Diabetes therefore, is a metabolic disease that can be well under control and reasonably managed with proper care, though it cannot be cured once it occurs (Thomas, 2005). Diabetes may present with characteristics symptoms such as polyuria, polydipsia, weight loss with sometimes polyphagia and blurred vision. Impairment of growth and susceptibility to certain infections may also accompany with chronic state of hyperglycemia. Acute lifethreating consequences of diabetes are hyperglycemia with ketoacidosis or non-ketotic hyperosmolar syndrome (JakJervell, 2000). Diabetes mellitus can lead to long term complications many of which can be fatal, if not prevented and all of which have the potential to reduce quality of life for people with diabetes (Journal of American Medical Association, JAMA, 2002). The underlying pathophysiology and management of both forms are different; a common feature is development of long-term micro and macro vascular complications such as retinopathy, nephropathy macro vascular disease peripheral and autonomic neuropathy. These complications are associated with increased morbidity and mortality (DCCT, 1993). Malnutrition is still a devastating problem in certain parts of the world although proportion and absolute number of chronically under-nourished people have declined. Under-nutrition remains as a serious problem among poor families and of under-developed nations, resulting from consumption of poor diet over a long period of time (Awan, 1997). Protein energy malnutrition has been a common health problem of the third world (Khan et al., 1990). Malnutrition has many adverse consequences. It is often argued that a malnourished is mentally and physically fatigued. He or she lacks in curiosity and is irresponsive to environmental situation. He is also frequently attacked by illness leading to higher absenteeism which is considered as another cause for poor performance (Berg, 1969). A proper diet is a fundamental element of therapy in all diabetic individuals. A diet recommended for a diabetic patient is, in fact a "balanced diet" for anyone. A balanced meal is a combination of carbohydrates, fats, proteins and fibers appropriate for the individual. A diet plan should be individualized according to his/her needs; it must be simple to understand and easy to follow. The primary goal of medical nutrition therapy of diabetics is to achieve metabolic control in order to prevent short-term and long-term complications of diabetes mellitus. Therefore the aims of nutritional intervention should include not only optimum control of blood glucose levels but also normalization of lipids and lipoprotein concentrations and blood pressure. The recent dietary recommendations of the American Diabetes Association for diabetics include an individualized approach based upon the diabetes management goals of each patient that takes into consideration preference of the patient and control of hyperglycemia and dyslipidemia. In consideration of the composition of the diet, besides a low saturated (high carbohydrate diet, a high monounsaturated fat diet may also be recommended (Grag, 1996). Intake of trans-fatty acids and cholesterol should be restricted and alcohol should be completely avoided in diabetic with dyslipidemia. Protein intakes should be between $15-20 \%$ of the total energy intake. Fiber rich sources of complex carbohydrates are preferred over refined sugars. The diet should be wholesome and provide the dietary allowances of all vitamins and minerals (www.bamboweb, 2005). A survey of nutritional status should show the relationship between food and nutrients, their use in the body and general health. It may be good, fair or poor, depending on the body ability to utilize these (Overt, 1980). Nutritional assessment is the process whereby the state of nutritional health of an individual or group of individuals is determined. Nutritional status is commonly assessed by anthropometric measurement, clinical examinations for ascertaining nutritional deficiencies and also biochemical assessment (J Am, 1969). In the present context, it is more important to assess the nutritional status of diabetes patients. As such the present study was undertaken to assess the nutritional status in relation to clinical presentations, anthropometrical measurements, hemoglobin level and dietary pattern of diabetes patients on three selected Diabetic centers in Kushtia district, Bangladesh.

\section{Materials and Methods}

\subsection{Study area and period}

The out-patient department based study was carried out at Kushtia Diabetic Shomity, Bheramara Diabetic Shomity and Diabetic Shomity Kumarkhali, Kushtia, Bangladesh. This descriptive cross-sectional study was carried out to evaluate that nutritional status of the diabetic patients influence by socio-economic level, dietary habits and physical activity from three diabetic centers, Kushtia during the period from August 2016 to July 2017. Total 282diabetes patients from both sexes $(n=282 ; 144$ men and 138 women) were selected for the study by using Simple Random Sampling Technique. 
2.2. Collection of data

All participants were informed of the purpose of the study and each patient signed a consent form. Data regarding anthropometric information and socioeconomic status like occupation, marital status, education, family size and monthly family income was collected by interviewing the subjects. All diabetic patients from out-patient departments of the three diabetic centers with the following criteria participated in the study: 1). having fasting blood sugar of $(7.0 \mathrm{mml} / \mathrm{L}) 126 \mathrm{mg} / \mathrm{dl}$ and above. 2). require insulin or oral hypoglycemic agents or both for the control of blood sugar. Patient's weight and height measurements were taken by the following anthropometric procedures (WHO, 1995). Body weight was measured with a digital weighting scale in kilogram. Height was taken with a measuring scale in centimeters. BMI was calculated by using the formula: Wt (in $\mathrm{kg}$ ) $/ \mathrm{Ht}\left(\right.$ in $\mathrm{m}^{2}$ ) = BMI (in $\mathrm{kg} / \mathrm{m}^{2}$ ). Assessment of nutritional status was done by Body Mass Index method (WHO, 1995). Respondents having BMI < 18.5 were considered as underweight, having BMI 18.5-24.9 as normal weight, having BMI 25.0-29.9 as over-weight and having BMI $>30$ as obese. Blood samples were taken from each patient for the estimation of blood glucose, hemoglobin, serum creatinine and lipid profile. The estimation was performed following the new WHO diagnostic criteria (Diabetes care, 1997). Dietary intakes of the participants were collected by an interviewer administered 24-hour recall in the past 24 hours. It was done face to face early in the morning before the patients eat any food. Just like the name implies, the patients were asked to recall all they ate the previous day. The parameters in the food recall table were as follow: food and drink consumed, time the food eaten and description of the food.

\subsection{Statistical analysis}

Data were checked, entered and analyzed using the computer program Statistical Package for Social Sciences (SPSS) version 22. The statistical analyses include frequencies and mean \pm SD. For all analyses, $p$ value $<0.05$ was considered statistically significant.

\section{Results and Discussion}

\subsection{Socio-demographic data}

A descriptive cross-sectional study was carried out among 282 diabetic patients selected randomly from three diabetic centers in Kushtia district. Socio-demographic profiles of diabetic patients are shown in Table 1.

Table 1. Percentage distribution of socio-demographic characteristics of the respondents (Diabetic Patients).

\begin{tabular}{llll}
\hline Characteristics & Male & Female & Total \\
\hline Age range (years) & & & \\
$<31$ & $6(4.2 \%)$ & $17(12.3 \%)$ & $23(8.2 \%)$ \\
$31-40$ & $17(11.8 \%)$ & $37(26.8 \%)$ & $54(19.1 \%)$ \\
$41-50$ & $34(23.6 \%)$ & $40(29.0 \%)$ & $74(26.2 \%)$ \\
$51-60$ & $47(32.6 \%)$ & $33(23.9 \%)$ & $80(28.4 \%)$ \\
$>60$ & $40(27.8 \%)$ & $11(8.0 \%)$ & $51(18.1 \%)$ \\
Total & $144(100 \%)$ & $138(100 \%)$ & $282(100 \%)$ \\
& & & \\
Place of residence & & $73(52.9 \%)$ & $142(50.4 \%)$ \\
Urban & $69(47.9 \%)$ & $65(47.1 \%)$ & $140(49.6 \%)$ \\
Rural & $75(52.1 \%)$ & $138(100 \%)$ & $282(100 \%)$ \\
Total & $144(100 \%)$ & & \\
& & $55(39.9 \%)$ & $84(29.8 \%)$ \\
Educational background & & $44(31.9 \%)$ & $79(28.0 \%)$ \\
No formal education & $29(20.1 \%)$ & $12(8.7 \%)$ & $40(14.2 \%)$ \\
Primary school & $35(24.3 \%)$ & $14(10.1 \%)$ & $33(11.7 \%)$ \\
Secondary school & $28(19.4 \%)$ & $13(9.4 \%)$ & $46(16.3 \%)$ \\
Intermediate school & $19(13.2 \%)$ & $138(100 \%)$ & $282(100 \%)$ \\
Graduate and above & $33(22.9 \%)$ & & \\
Total & $144(100 \%)$ & $1(0.7 \%)$ & $3(1.1 \%)$ \\
& & $129(93.5 \%)$ & $267(94.7 \%)$ \\
Marital status & & & \\
Unmarried & & & \\
Married & $138(95)$ & & \\
& & & \\
\hline
\end{tabular}




\begin{tabular}{|c|c|c|c|}
\hline Characteristics & Male & Female & Total \\
\hline Widow & $4(2.8 \%)$ & $6(4.3 \%)$ & $10(3.5 \%)$ \\
\hline Divorced & $0(0.0 \%)$ & $2(1.4 \%)$ & $2(0.7 \%)$ \\
\hline Total & $144(100 \%)$ & $138(100 \%)$ & $282(100 \%)$ \\
\hline \multicolumn{4}{|c|}{ No. of household members } \\
\hline$\leq 3$ & $58(40.3 \%)$ & $65(47.1 \%)$ & $123(43.6 \%)$ \\
\hline $4-6$ & $75(52.1 \%)$ & $68(49.3 \%)$ & $143(50.7 \%)$ \\
\hline$>6$ & $11(7.6 \%)$ & $5(3.6 \%)$ & $16(5.7 \%)$ \\
\hline Total & $144(100 \%)$ & $138(100 \%)$ & $282(100 \%)$ \\
\hline \multicolumn{4}{|l|}{ Occupation } \\
\hline Unemployed & $2(1.4 \%)$ & $124(89.9 \%)$ & $126(44.7 \%)$ \\
\hline Student & $1(0.7 \%)$ & $0(0.0 \%)$ & $1(0.4 \%)$ \\
\hline Farmer & $34(23.6 \%)$ & $0(0.0 \%)$ & $34(12.1 \%)$ \\
\hline Trader & $55(38.2 \%)$ & $1(0.7 \%)$ & $56(19.9 \%)$ \\
\hline Junior civil servant & $14(9.7 \%)$ & $7(5.1 \%)$ & $21(7.4 \%)$ \\
\hline Senior civil servant & $18(12.5 \%)$ & $5(3.6 \%)$ & $23(8.2 \%)$ \\
\hline Retire/ Pensioner & $17(11.8 \%)$ & $1(0.7 \%)$ & $18(6.4 \%)$ \\
\hline Others & $3(2.1 \%)$ & $0(0.0)$ & $3(1.1 \%)$ \\
\hline Total & $144(100 \%)$ & $138(100 \%)$ & $282(100 \%)$ \\
\hline \multicolumn{4}{|c|}{ Monthly household income in Taka (BDT) } \\
\hline$<4000$ & $15(10.4 \%)$ & $4(2.9 \%)$ & $19(6.7 \%)$ \\
\hline $4000-9000$ & $38(26.4 \%)$ & $36(26.1 \%)$ & $74(26.2 \%)$ \\
\hline $9001-14000$ & $20(13.9 \%)$ & $44(31.9 \%)$ & $64(22.7 \%)$ \\
\hline $14001-19000$ & $29(20.1 \%)$ & $29(21.0 \%)$ & $58(20.6 \%)$ \\
\hline$>19000$ & $42(29.2 \%)$ & $25(18.1 \%)$ & $67(23.8 \%)$ \\
\hline Total & $144(100 \%)$ & $138(100 \%)$ & $282(100 \%)$ \\
\hline \multicolumn{4}{|c|}{ Socio-economic status } \\
\hline Upper & $43(29.9 \%)$ & $25(18.1 \%)$ & $68(24.1 \%)$ \\
\hline Upper - middle & $28(19.4 \%)$ & $29(21.0 \%)$ & $57(20.2 \%)$ \\
\hline Middle & $21(14.6 \%)$ & $43(31.2 \%)$ & $64(22.7 \%)$ \\
\hline Upper - lower & $36(25.0 \%)$ & $37(26.8 \%)$ & $73(25.9 \%)$ \\
\hline Lower & $16(11.1 \%)$ & $4(2.9 \%)$ & $20(7.1 \%)$ \\
\hline Total & $144(100 \%)$ & $138(100 \%)$ & $282(100 \%)$ \\
\hline
\end{tabular}

Table 1 has shown that a total of $51.1 \%$ of the subjects were males and $48.9 \%$ were females. Only $8.2 \%$ of the subjects $(4.2 \%$ were male and $12.3 \%$ were female) were within the age range of 30 years and below. Another $28.4 \%$ were within the age range of 51 to 60 years. About $32.6 \%$ were male and $23.9 \%$ were female subjects were within the age range of 51 to 60 years. About $50.4 \%$ of the diabetic patients were resided in urban area and $49.6 \%$ were resided in rural area. A total of $28.0 \%$ of the subjects (male were $24.3 \%$ and female were $31.9 \%$ ) had primary education and about $95 \%$ of the subjects (94.7\%) were married. About $44.7 \%$ of subjects were unemployed and $19.9 \%$ were traders. About half of the patient $(50.7 \%)$ had 4 to 6 family members. About $23.8 \%$ families' monthly income were more than 19000 BDT. About $44.3 \%$ of the subjects were high income level (24.1\% were upper and $20.2 \%$ were upper-middle socio-economic status), $22.7 \%$ were middle income level and $33.0 \%$ were low income level (25.9\% were upper-lower and $7.1 \%$ were lower socio-economic status).

\subsection{Biophysical characteristics}

Biophysical characteristics of male and female diabetic patients in Kushtia district are shown in Table 2. 
Table 2. Percentage distribution of biophysical characteristics of the respondents (Diabetic Patients).

\begin{tabular}{llll}
\hline Characteristics & Male & Female & Total \\
\hline Systolic blood pressure & & & \\
$=140$ normal & $91(63.2 \%)$ & $109(79.0 \%)$ & $200(70.9 \%)$ \\
$>140$ high & $53(36.8 \%)$ & $29(21.0 \%)$ & $82(29.1 \%)$ \\
Total & $144(100 \%)$ & $138(100 \%)$ & $282(100 \%)$ \\
& & & \\
Diastolic blood pressure & & & \\
$=90$ normal & $88(61.1 \%)$ & $94(68.1 \%)$ & $182(64.5 \%)$ \\
$>90$ high & $56(38.9 \%)$ & $44(31.9 \%)$ & $100(35.5 \%)$ \\
Total & $144(100 \%)$ & $138(100 \%)$ & $282(100 \%)$ \\
& & & \\
Smoking & & & \\
Yes & $74(51.4 \%)$ & $0(0.0 \%)$ & $208(26.2 \%)$ \\
No & $70(48.6 \%)$ & $138(100 \%)$ & $282(100 \%)$ \\
Total & $144(100 \%)$ & $138(100 \%)$ & \\
& & & \\
Exercise & & & \\
Yes & $92(63.9 \%)$ & $52(59.4 \%)$ & $174(61.7 \%)$ \\
No & $52(36.1 \%)$ & $138(40.6 \%)$ & $282(100 \%)$ \\
Total & $144(100 \%)$ & & \\
\hline
\end{tabular}

Table 2 has explained that, a total of $29.1 \%$ of the subjects had high systolic blood pressure and $35.5 \%$ of the subjects had high diastolic blood pressure. Again about $36.8 \%$ and $38.9 \%$ of the diabetic male had high systolic and diastolic blood pressure, whereas $21.0 \%$ and $31.9 \%$ of the diabetic female had high systolic and diastolic blood pressure. So the result shows that male diabetic patients were more prevalent for high systolic and diastolic blood pressure than that of female. About $73.8 \%$ of the total subjects were non-smoker. About $63.9 \%$ of the male subjects and $59.4 \%$ of the female subjects had experience of regular physical exercise.

\subsection{Anthropometric indices}

Anthropometric characteristics of the diabetic patients are shown in Table 3, Table 4 and Table 5.

Table 3. Distribution of mean body mass index (BMI) of the respondents (Diabetic Patients) according to sex.

BMI ranges $\left(\mathrm{kg} / \mathrm{m}^{2}\right) \quad$ Variables

\begin{tabular}{|c|c|c|c|c|c|c|c|}
\hline & $N$ & Male & $N$ & Female & $N$ & $(\%)$ & Mean \\
\hline «18.5 (underweight) & 9 & $16.30 \pm 1.98$ & 4 & $18.05 \pm 0.38$ & 13 & $4.6 \%$ & \\
\hline $18.5-24.9$ (Normal) & 86 & $21.92 \pm 1.67$ & 52 & $22.02 \pm 1.93$ & 138 & $48.9 \%$ & \\
\hline 25-29.9 (Overweight) & 46 & $26.71 \pm 1.24$ & 60 & $27.00 \pm 1.46$ & 106 & $37.6 \%$ & \\
\hline$>30$ (Obesity) & 3 & $32.37 \pm 1.17$ & 22 & $33.07 \pm 2.92$ & 25 & $8.9 \%$ & \\
\hline Mean & 144 & $23.32 \pm 3.47$ & 138 & $25.83 \pm 4.46$ & 282 & $100.0 \% 24.55 \pm 4.18$ & .000 \\
\hline
\end{tabular}

Table 3 has revealed that the mean BMI of the males was $23.32 \pm 3.47 \mathrm{~kg} / \mathrm{m} 2$ and that of the females was $25.83 \pm 4.46 \mathrm{~kg} / \mathrm{m} 2$. The BMI value for the females was significantly $(\mathrm{p}<0.05)$ higher than that of males. A total of $37.6 \%(n=106)$ of the patients were overweight, $8.9 \%(n=25)$ were obese, $4.6 \%(n=13)$ were underweight and $48.9 \%(n=138)$ were normal. 
Table 4. Cross tabulation of BMI with sex, place of residence, educational levels, occupation and socioeconomic status of the respondents (Diabetic Patients).

\begin{tabular}{|c|c|c|c|c|c|}
\hline Variables & $<18.5$ & $18.5-24.9$ & $25.0-29.9$ & $>30.0$ & Total \\
\hline \multicolumn{6}{|l|}{ Sex } \\
\hline Males & $9(69.2 \%)$ & $86(62.3 \%)$ & $46(43.4 \%)$ & $3(12.0 \%)$ & $144(51.1 \%)$ \\
\hline Female & $4(30.8 \%)$ & $52(37.7 \%)$ & $60(56.6 \%)$ & $22(88.0 \%)$ & $138(48.9 \%)$ \\
\hline Total & $13(100 \%)$ & $138(100 \%)$ & $106(100 \%)$ & $25(100 \%)$ & $282(100 \%)$ \\
\hline \multicolumn{6}{|l|}{ Place of residence } \\
\hline Urban & $1(7.7 \%)$ & $46(33.3 \%)$ & $76(71.7 \%)$ & $19(76.0 \%)$ & $142(50.4 \%)$ \\
\hline Rural & $12(92.3 \%)$ & $92(66.7 \%)$ & $30(28.3 \%)$ & $6(24.0 \%)$ & $140(49.6 \%)$ \\
\hline Total & $13(100 \%)$ & $138(100 \%)$ & $106(100 \%)$ & $25(100 \%)$ & $282(100 \%)$ \\
\hline \multicolumn{6}{|l|}{ Educational background } \\
\hline No formal education & $7(53.8 \%)$ & $35(25.4 \%)$ & $35(33.0 \%)$ & $7(28.0 \%)$ & $84(29.8 \%)$ \\
\hline Primary school & $5(38.5 \%)$ & $34(24.6 \%)$ & $34(32.1 \%)$ & $6(24.0 \%)$ & $79(28.0 \%)$ \\
\hline Secondary school & $0(0.0 \%)$ & $27(19.6 \%)$ & $9(8.5 \%)$ & $4(16.0 \%)$ & $40(14.2 \%)$ \\
\hline Intermediate school & $1(7.7 \%)$ & $16(11.6 \%)$ & $13(12.3 \%)$ & $3(12.0 \%)$ & $33(11.7 \%)$ \\
\hline Graduate and above & $0(0.0 \%)$ & $26(18.8 \%)$ & $15(14.2 \%)$ & $5(20.0 \%)$ & $46(16.3 \%)$ \\
\hline Total & $13(100 \%)$ & $138(100 \%)$ & $106(100 \%)$ & $25(100 \%)$ & $282(100 \%)$ \\
\hline \multicolumn{6}{|l|}{ Occupation } \\
\hline Unemployed & $4(30.7 \%)$ & $45(32.7 \%)$ & $59(55.7 \%)$ & $18(72.0 \%)$ & $126(44.7 \%)$ \\
\hline Student & $0(0.0 \%)$ & $1(0.7 \%)$ & $0(0.0 \%)$ & $0(0.0 \%)$ & $1(0.4 \%)$ \\
\hline Farmer & $6(46.2 \%)$ & $22(15.9 \%)$ & $5(4.7 \%)$ & $1(4.0 \%)$ & $34(12.1 \%)$ \\
\hline Trader & $3(23.1 \%)$ & $29(21.0 \%)$ & $22(20.8 \%)$ & $2(8.0 \%)$ & $56(19.9 \%)$ \\
\hline Junior civil servant & $0(0.0 \%)$ & $12(8.7 \%)$ & $6(5.7 \%)$ & $3(12.0 \%)$ & $21(7.4 \%)$ \\
\hline Senior civil servant & $0(0.0 \%)$ & $15(10.9 \%)$ & $8(7.5 \%)$ & $0(0.0 \%)$ & $23(8.2 \%)$ \\
\hline Retire/Pensioner & $0(0.0 \%)$ & $12(8.7 \%)$ & $5(4.7 \%)$ & $1(4.0 \%)$ & $18(6.4 \%)$ \\
\hline Others & $0(0.0 \%)$ & $2(1.4 \%)$ & $1(0.9 \%)$ & $0(0.0 \%)$ & $3(1.1 \%)$ \\
\hline Total & $13(100 \%)$ & $138(100 \%)$ & $106(100 \%)$ & $25(100 \%)$ & $282(100 \%)$ \\
\hline \multicolumn{6}{|l|}{ Socio-economic status } \\
\hline Upper & $0(0.0 \%)$ & $35(25.4 \%)$ & $23(21.7 \%)$ & $10(40.0 \%)$ & $68(24.1 \%)$ \\
\hline Upper-middle & $2(15.4 \%)$ & $28(20.3 \%)$ & $23(21.7 \%)$ & $4(16.0 \%)$ & $57(20.2 \%)$ \\
\hline Middle & $4(30.7 \%)$ & $24(17.4 \%)$ & $31(29.3 \%)$ & $5(20.0 \%)$ & $64(22.7 \%)$ \\
\hline Upper-lower & $6(46.2 \%)$ & $37(26.8 \%)$ & $24(22.6 \%)$ & $6(24.0 \%)$ & $73(25.9 \%)$ \\
\hline Lower & $1(7.7 \%)$ & $14(10.1 \%)$ & $5(4.7 \%)$ & $0(0.0 \%)$ & $20(7.1 \%)$ \\
\hline Total & $13(100 \%)$ & $138(100 \%)$ & $106(100 \%)$ & $25(100 \%)$ & $282(100 \%)$ \\
\hline
\end{tabular}

Table 4 has shown the cross tabulation of BMI of subjects with sex, place of residence, educational level, occupation and socio-economic status. Among 13 diabetics who were underweight, $69.2 \%$ were males and $30.8 \%$ were females. Among those who were of normal weight $62.3 \%$ were males and $37.7 \%$ were females. Among the 25 diabetics who were obese $12.0 \%$ were males while $88.0 \%$ were females. As many as $56.6 \%$ of female were overweight, among the overweight category while $43.4 \%$ male were overweight. About $7.7 \%$ of the diabetics who lived in urban area were underweight while $92.3 \%$ who lived in rural were underweight. About $33.3 \%$ of diabetics who were normal weight live in the urban and $66.7 \%$ in the rural. Among the 106 subjects within the overweight category $71.7 \%$ of those that lived in urban area were overweight while $28.3 \%$ were from the rural area. Among the 25 subjects who were obese $76.0 \%$ were from the urban while $24.0 \%$ were from the rural area. Among 106 diabetics who were overweight $8.5 \%$ had secondary education while $33.0 \%$ had no formal education. In obese category, among 25 subjects $28.0 \%$ had no formal education, $16.0 \%$ had secondary education, while $20.0 \%$ of the subjects that had graduate and above. Unemployed respondents showed overweight $59(55.7 \%)$ more and among 25 obese patients $72.0 \%$ were unemployed. On the other hand among 13 underweight respondents more $(46.2 \%)$ were farmer. But no underweight with high family income could be detected. Among 25 obese patients more (40.0\%) were from upper socio-economic status.

Table-5 shows relationship between the socioeconomic variables and BMI of diabetic patients. The BMI of patients was significant in different sex, resident and occupation. There were no significant differences ( $p>$ 0.05 ) in the BMI of patients in different educational attainments and age range. 
Table 5. Relationship between respondent's (Diabetic Patients) variable and mean BMI.

\begin{tabular}{|c|c|c|c|}
\hline Variables & $\mathrm{N}$ & BMI & P. value \\
\hline \multicolumn{4}{|l|}{$\operatorname{Sex}$} \\
\hline Male & 144 & $23.32 \pm 3.47^{\mathbf{b}}$ & \\
\hline Female & 138 & $25.83 \pm 4.46^{\mathbf{a}}$ & \\
\hline Mean & 282 & $24.55 \pm 4.18$ & .000 \\
\hline \multicolumn{4}{|l|}{ Age range (years) } \\
\hline$<31$ & 23 & $25.63 \pm 5.06^{\mathrm{a}}$ & \\
\hline $31-40$ & 54 & $25.28 \pm 4.27^{\mathrm{a}}$ & \\
\hline $41-50$ & 74 & $25.10 \pm 4.28^{\mathrm{a}}$ & \\
\hline $51-60$ & 80 & $23.71 \pm 3.99^{\mathrm{a}}$ & \\
\hline 61 and above & 51 & $23.79 \pm 3.49^{\mathrm{a}}$ & \\
\hline Mean & 282 & $24.55 \pm 4.18$ & .051 \\
\hline \multicolumn{4}{|l|}{ Place of residence } \\
\hline Urban & 142 & $26.15 \pm 3.97^{\mathbf{b}}$ & \\
\hline Rural & 140 & $22.92 \pm 3.74^{\mathrm{a}}$ & \\
\hline Mean & 282 & $24.55 \pm 4.18$ & .000 \\
\hline \multicolumn{4}{|l|}{ Educational background } \\
\hline No formal education & 84 & $24.26 \pm 4.58^{\mathrm{a}}$ & \\
\hline Primary school & 79 & $24.68 \pm 3.64^{\mathrm{a}}$ & \\
\hline Secondary school & 40 & $24.29 \pm 4.67^{\mathrm{a}}$ & \\
\hline Intermediate school & 33 & $24.58 \pm 4.00^{\mathrm{a}}$ & \\
\hline Graduate and above & 46 & $25.05 \pm 4.04^{\mathrm{a}}$ & \\
\hline Mean & 282 & $24.55 \pm 4.18$ & .860 \\
\hline \multicolumn{4}{|l|}{ Occupation } \\
\hline Unemployed & 126 & $25.72 \pm 4.31^{\mathbf{b}}$ & \\
\hline Student & 1 & $21.60 \pm 0.00^{\mathbf{b}}$ & \\
\hline Farmer & 34 & $21.78 \pm 3.95^{\mathbf{b}}$ & \\
\hline Trader & 56 & $24.20 \pm 3.53^{b}$ & \\
\hline Junior civil servant & 21 & $25.35 \pm 4.97^{\mathbf{b}}$ & \\
\hline Senior civil servant & 23 & $23.59 \pm 2.89^{\mathbf{b}}$ & \\
\hline Retire/Pensioner & 18 & $23.38 \pm 3.13^{\mathbf{b}}$ & \\
\hline Others & 3 & $22.93 \pm 2.74^{\mathrm{a}}$ & \\
\hline Mean & 282 & $24.55 \pm 4.18$ & .000 \\
\hline
\end{tabular}

$\boldsymbol{a b}$ : values with different subscript letters in the same column are significantly different $(P<0.05)$.

\subsection{Biochemical tests}

Biochemical indices of the diabetic patients are shown in Table 6.

Table 6. Mean biochemical indices of the respondents (Diabetic Patients).

\begin{tabular}{llllll}
\hline $\begin{array}{l}\text { Biochemical indices: } \\
\text { Combined range }\end{array}$ & Male & Female & Male \& female & P. value & Normal \\
\hline Blood hemoglobin level (g/dl) & $12.85 \pm 1.48$ & $12.11 \pm 1.36$ & $12.49 \pm 1.47$ & .000 & M: $14-18, \mathrm{~F}: 11.5-16.5$ \\
Fasting blood glucose (mmol/L) & $8.69 \pm 1.48$ & $9.04 \pm 1.84$ & $8.86 \pm 1.67$ & .080 & $<7.0$ \\
Bl. Glucose 2 hours after breakfast & $13.86 \pm 2.92$ & $14.01 \pm 2.84$ & $13.94 \pm 2.88$ & .673 & $<11.1$ \\
Serum creatinin $(\mathrm{mg} / \mathrm{dl})$ & $1.17 \pm 1.05$ & $1.26 \pm 1.05$ & $1.22 \pm 1.05$ & .480 & $0.70-1.20$ \\
Total cholesterol (mg/dl) & $198.49 \pm 51.87$ & $195.92 \pm 45.96$ & $197.23 \pm 48.99$ & .660 & Up to 200 \\
LDL (mg/dl) & $119.66 \pm 48.34$ & $114.65 \pm 40.45$ & $117.21 \pm 44.65$ & .347 & $<150$ \\
HDL (mg/dl) & $35.31 \pm 5.53$ & $34.59 \pm 5.21$ & $34.96 \pm 5.38$ & .263 & $\mathrm{M}:>45, \mathrm{~F}:>35$ \\
Triglycerides $(\mathrm{mg} / \mathrm{dl})$ & $217.57 \pm 70.95$ & $233.37 \pm 76.63$ & $225.30 \pm 74.08$ & .073 & $50-150$ \\
\hline
\end{tabular}

HDL = High density lipoprotein

LDL $=$ Low density lipoprotein 
The mean blood hemoglobin level was $12.49 \pm 1.47 \mathrm{~g} / \mathrm{dl}$, in which male hemoglobin level was $12.85 \pm 1.48 \mathrm{~g} / \mathrm{dl}$ and of female was $12.11 \pm 1.36 \mathrm{~g} / \mathrm{dl}$. The mean fasting blood glucose level of the patients was $8.86 \pm 1.67 \mathrm{mmol} / \mathrm{L}$ and blood glucose level two hours after breakfast was $13.94 \pm 2.88 \mathrm{mmol} / \mathrm{L}$. The mean serum creatinine level of the male patients were $1.17 \pm 1.05 \mathrm{mg} / \mathrm{dl}$ and female were $1.26 \pm 1.05 \mathrm{mg} / \mathrm{dl}$. The patients mean total cholesterol, low density lipoprotein; high density lipoprotein and triglyceride levels were $197.23 \pm 48.99 \mathrm{mg} / \mathrm{dl}$, $117.21 \pm 44.65 \mathrm{mg} / \mathrm{dl}, 34.96 \pm 5.38 \mathrm{mg} / \mathrm{dl}$ and $225.30 \pm 74.08 \mathrm{mg} / \mathrm{dl}$ respectively.

\subsection{Clinical findings}

The distributions of family history of chronic diseases of the diabetics have shown in Table 7.

Table 7. Family history of chronic diseases of the respondents (Diabetic Patients) according to sex.

\begin{tabular}{llll}
\hline $\begin{array}{l}\text { Variables: } \\
\text { Family history of chronic diseases }\end{array}$ & Male & Female & Total \\
\hline None & $71(49.3 \%)$ & $39(28.3 \%)$ & $110(39.0 \%)$ \\
DM & $8(5.5 \%)$ & $11(8.0 \%)$ & $19(6.7 \%)$ \\
HTN & $35(24.3 \%)$ & $39(28.3 \%)$ & $74(26.3 \%)$ \\
HTN and DM & $12(8.3 \%)$ & $26(18.7 \%)$ & $38(13.5 \%)$ \\
HTN, DM and CVD & $1(0.7 \%)$ & $6(4.3 \%)$ & $7(2.5 \%)$ \\
HTN, DM and Asthma & $7(4.9 \%)$ & $11(8.0 \%)$ & $18(6.4 \%)$ \\
DM and Renal disease & $3(2.1 \%)$ & $3(2.2 \%)$ & $6(2.1 \%)$ \\
HTN, DM and renal disease & $7(4.9 \%)$ & $3(2.2 \%)$ & $10(3.5 \%)$ \\
Total & $144(100 \%)$ & $138(100 \%)$ & $282(100 \%)$ \\
\hline
\end{tabular}

HTN $=$ Hypertension

$\mathrm{DM} \quad=\quad$ Diabetes Mellitus

$\mathrm{CVD}=$ Cerebral Vascular Disease

About $39.0 \%$ of the diabetic patient had no family history of chronic diseases. Only $6.7 \%$ of the diabetic patient had family history of diabetes alone and $26.3 \%$ patients had family history of hypertension alone. About $13.5 \%$ and $2.5 \%$ patients had family history of hypertension and hypertension with CVD along with diabetes. About $2.1 \%$ patients had family history of renal disease and $3.5 \%$ had hypertension and renal disease along with diabetes.

\subsection{Dietary results}

The food consumption patterns of the respondents are shown in Table 8.

Table 8. Percent distribution of the respondents (Diabetic Patients) by consumption frequencies of selected food groups (Multiple responses).

\begin{tabular}{llll}
\hline Food groups & Male (133) & Female (126) & Total (259) \\
\hline Rice & $132(99.2 \%)$ & $125(99.2 \%)$ & $257(99.2 \%)$ \\
Wheat flour/ Bread & $120(90.2 \%)$ & $118(93.6 \%)$ & $238(91.9 \%)$ \\
Meat & $30(22.5 \%)$ & $27(21.4 \%)$ & $57(22.0 \%)$ \\
Fish & $82(61.6 \%)$ & $90(71.5 \%)$ & $172(66.5 \%)$ \\
Egg & $79(59.4 \%)$ & $73(57.9 \%)$ & $152(58.7 \%)$ \\
Pulses, nuts & $108(81.2 \%)$ & $98(77.8 \%)$ & $206(79.5 \%)$ \\
Green leafy vegetables & $131(98.5 \%)$ & $125(99.2 \%)$ & $256(98.8 \%)$ \\
Fruits & $50(37.5 \%)$ & $72(57.0 \%)$ & $122(47.2 \%)$ \\
Milk and milk products & $36(27.0 \%)$ & $52(41.2 \%)$ & $88(34.0 \%)$ \\
Tea, biscuits & $61(45.8 \%)$ & $17(13.5 \%)$ & $78(30.0 \%)$ \\
Fats and oils & $4(3.0 \%)$ & $3(2.4 \%)$ & $7(2.7 \%)$ \\
Dairy products & $23(17.3 \%)$ & $27(21.4 \%)$ & $50(19.3 \%)$ \\
\hline
\end{tabular}

Majority (99.2\%) consumed rice once per day while few (34.0\%) consumed milk and milk product once per day. Averagely $(58.7 \%)$ of the respondents consumed egg while majority $(98.8 \%)$ consumed green leafy vegetables once per day. Fried and dairy products were consumed by $19.3 \%$ once per day while fruits were consumed by $47.2 \%$ respondents once per day. Approximately $79.5 \%$ consumed pulses and nuts once daily while $30.0 \%$ consumed tae and biscuit once per day. Majority of the patients $(66.5 \%)$ consumed fish once per 
day while few $(22.0 \%)$ consumed red meat once per day. About only $2.7 \%$ patients consumed fats (butter, margarine) once per day.

\section{Conclusions}

Based on the findings of the study, it could be concluded that Middle to elder age group (41-60 years) appeared to suffer more from diabetes with no sex differences (male were $56.2 \%$ and female were $54.1 \%$ ). No underweight with high family income might be explained as an association of more calorie intake and less physical activities. Among the diabetic patients, retired and unemployed persons appeared particularly vulnerable to become overweight to obese and on the other hand younger patients, poor education, lower income group and patients consuming low calorie were prone to develop under nutrition. So, health education should be aimed to enhance awareness of particularly rural and illiterate people for regular visit to nearby diabetic center and to strictly adhere to dietician's advice.

Combination of intensive nutrition education, medical nutrition therapy, prescribed medication and counseling are keys to successful management of diabetes mellitus. People should be able to discipline themselves to eat less sugar containing food like chocolate, pastries and also eating of junk food which has no nutrients. The older people need to exercise regularly to avoid the ailment because lack of it can lead to obesity which is one of the complications of diabetes. The obese diabetics must reduce weight and adiposity to be successful in the management of their diabetes.

\section{Conflict of interest}

None to declare.

\section{References}

Alberti KG NM and PZ Zimmet, 1998. Definition, diagnosis and classification of diabetes mellitus and its complications part 1: diagnosis and classification of diabetes mellitus provisional report of a WHO consultation. Diabetes Med., 15: 539 - 553.

Awan JA, 1997. Food and Nutrition. Published by Moon Plaza.Cheniot Bazar, pp. 5-7, 1997.

Berg A, 1969. The nutrition Factor. $7^{\text {th }}$ ed. The Brookings institute; Massachusettes:1969. p. 45.

Committee on Goals of Education for Dietetics, 1969. Goals of the Lifetime Education of the Dietitian. J. Am. Diet. Assoc., 54: 92.

DCCT Research Group, 1993. The effect of intensive treatment of diabetes on the development and progression of long-term complications in insulin-dependent diabetes mellitus. N Engl. J. Med., 329: 977-986.

Writing Team for the Diabetes Control and Complications Trial/Epidemiology of Diabetes Interventions and Complications Research Group, 2002. Effect of Intensive Therapy on the Microvascular Complications of Type 1 Diabetes Mellitus. JAMA, 287: 2563-2569.

Grag A, 1996. Optimum dietary therapy for patients with non-insulin dependent Diabetes Mellitus. The Endocrinologist, 6:1 30-36.

Gibney M, IA Macdonald and HM Roche, 2004. Nutrition and Metabolism. Blackwell Publishing Company 332.

Gordon Edin and Eric Golanty, 2009. Health and wellness. p.140.

JakJervell, 2000. An update on Diabetes, including HbA1c and micro albumin, First edition August 2000.

Khan AZ, NL Singh, SB Hassan, SN Sinta and M Zaheer, 1990. Anthropometric measurements in rural school children. J. R. Soc. Health, 11:184-186.

Overt JC, 1980. Community Nutrition. 5th ed. John Wiley Sons Inc; Canada: 1980. p.15-24.

Thomas MS, 2005. Relationship between dietary fiber composition in food and glycemic index.American Journal of Nutrition. pp. $72-75$.

The Expert Committee on the diagnosis and classification of diabetes mellitus, 1997. Report of the Expert Committee on the diagnosis and classification of diabetes mellitus. Diabetes Care, 20:1183 - 1197.

World Health Organization, 1995. Report of a WHO Expert Committee. Physical status: the use and interpretation of anthropometry. WHO Technical. Report Series No 854. Geneva: World Health Organization.

www.bamboweb. 2005. 